\title{
Effect of Er:YAG laser enamel conditioning and moisture on the microleakage of a hydrophilic sealant
}

\author{
Zeynep Aslı Güçlü ${ }^{1}$. Andrew Paul Hurt ${ }^{2}$. Nazmiye Dönmez ${ }^{3} \cdot$ Nichola Jayne Coleman $^{2}$
}

Received: 14 July 2017 / Accepted: 9 September 2017 / Published online: 13 December 2017

(c) The Author(s) 2017. This article is an open access publication

\begin{abstract}
For a given sealant, successful pit and fissure sealing is principally governed by the enamel conditioning technique and the presence of moisture contamination. A new generation of hydrophilic resin sealants is reported to tolerate moisture. This study investigates the impact of Er:YAG laser pre-conditioning and moisture contamination on the microleakage of a recent hydrophilic sealant. Occlusal surfaces of extracted human molars were either acid etched $(n=30)$, or successively lased and acid etched $(n=30)$. Ten teeth from each group were either air-dried, water-contaminated, or saliva-contaminated prior to sealing with UltraSeal $\mathrm{XT}^{\circledR}$ hydro ${ }^{\mathrm{TM}}$. Samples were inspected for penetration of fuchsin dye following 3000 thermocycles between 5 and $50{ }^{\circ} \mathrm{C}$, and the enamel-sealant interfaces were observed by scanning electron microscopy (SEM). Significant differences in microleakage were evaluated using the Mann-Whitney $U$ test with Bonferroni adjustment $(p=0.05)$. Laser pre-conditioning significantly reduced dye penetration irrespective of whether the enamel surface was moist or dry. Microleakage of water-contaminated acid etched teeth was significantly greater than that of their air-dried or saliva-contaminated counterparts. SEM analysis demonstrated good adaptation in all groups with the exception of water-contaminated acid etched teeth which exhibited relatively wide gaps. In conclusion, this hydrophilic sealant tolerates the presence of saliva, although water was found to impair its sealing ability. Laser pre-conditioning significantly decreases microleakage in all cases.
\end{abstract}

Keywords Hydrophilic sealant $\cdot$ Laser $\cdot$ Microleakage $\cdot$ Moisture $\cdot$ Saliva

\section{Introduction}

A wide range of light-cured resin-based sealants is commercially available for the isolation and defence of occlusal surfaces of molars and premolars $[1,2]$. The majority of these pit and fissure sealants are hydrophobic materials that bond to etched air-dried enamel via micromechanically interlocking tags. Moisture contamination compromises the quality of adhesion at the sealant-enamel interface, and is a common challenge encountered in paediatric dentistry where patient compliance is low [3]. To address this problem, hydrophilic

Nichola Jayne Coleman

n.coleman@gre.ac.uk

1 Department of Paediatric Dentistry, Faculty of Dentistry, Erciyes University, Kayseri, Turkey

2 Department of Pharmaceutical, Chemical and Environmental Sciences, Faculty of Engineering and Science, University of Greenwich, Chatham Maritime, Kent, UK

3 Department of Dental Diseases and Treatment, Bezmiâlem Vakif University, Istanbul, Turkey sealants have appeared on the market during the past decade which are specifically designed to be placed on moist enamel [3, 4].

Current research has indicated that the application of laser ablation as an adjunct to traditional phosphoric acid etching may improve the adhesion, adaptation, retention, and resistance to microleakage of resin-based sealants $[3,5]$. Recent clinical and in vitro studies support the use of laser ablation prior to acid etching [3-6], although these findings are not unanimously confirmed [7-9] In practice, the effectiveness of laser pre-conditioning appears to depend on many factors relating to the rheological and physicochemical properties of the particular sealant, lasing parameters and operator technique.

The principal objectives of this study were to investigate the impact of laser pre-conditioning and moisture contamination on the resistance to microleakage of the new hydrophilic self-adhesive sealant, UltraSeal XT ${ }^{\circledR}$ hydro $^{\mathrm{TM}}$ (Ultradent Products, USA) [10], in vitro. The occlusal surfaces of extracted human molars were either acid etched $(n=30)$, or successively lased and acid etched $(n=30)$. 
Ten teeth from each group were then either air-dried, watercontaminated, or saliva-contaminated prior to sealing with UltraSeal $\mathrm{XT}^{\circledR}$ hydro $^{\mathrm{TM}}$. The samples were inspected for microleakage using fuchsin dye penetration following 3000 thermocycles between 5 and $50{ }^{\circ} \mathrm{C}$. Microleakage scores were analysed using the Kruskal-Wallis test and Mann-Whitney $U$ test with Bonferroni adjustment. The following null hypotheses were tested $(p=0.05)$ : (1) there is no difference in microleakage among traditionally acid etched teeth that are either air-dried, water-contaminated or saliva-contaminated; (2) enamel pre-conditioning by laser ablation prior to acid etching has no impact on resistance to microleakage; and (3) the presence of moisture does not influence microleakage of teeth that have been successively lased and acid etched.

During this study, the nature of the enamel-sealant interface was also observed by scanning electron microscopy (SEM) with energy-dispersive X-ray (EDX) analysis.

\section{Materials and methods}

Ethical approval for this project was obtained on the 1st of October 2014 by the Ethical Committee of Bezmiâlem Vakif University (reference number 71306642/050-01-04/282). The study was performed in accordance with the ethical standards laid down in the 1964 Declaration of Helsinki and its later amendments.

\section{Sample preparation}

Sixty sound extracted human molar teeth were obtained from patients with orthodontic or periodontal problems who had provided their written informed consent. The teeth were debrided with manual scaling instruments, cleaned with bristle brush and pumice paste and stored in distilled water for up to 5 days. The teeth were then randomly divided into 6 groups, as indicated in Table 1. All samples were prepared by the same operator.

The occlusal surfaces of Group I teeth were acid etched for $20 \mathrm{~s}$ with $35 \%$ phosphoric acid gel (UltraSeal $\mathrm{XT}^{\circledR}$ hydro $^{\mathrm{TM}}$, Ultradent Products, USA), rinsed and air-dried.

Table 1 Experimental groups

\begin{tabular}{llll}
\hline Group & $n$ & Enamel pre-treatment & Surface condition \\
\hline I & 10 & Acid etch & Dry \\
II & 10 & Acid etch & Moist with water \\
III & 10 & Acid etch & Moist with saliva \\
IV & 10 & Lase and acid etch & Dry \\
V & 10 & Lase and acid etch & Moist with water \\
VI & 10 & Lase and acid etch & Moist with saliva \\
\hline
\end{tabular}

The UltraSeal XT ${ }^{\circledR}$ hydro ${ }^{\mathrm{TM}}$ sealant (Ultradent Products, USA) was then applied, according to the manufacturer's instructions and light cured for $20 \mathrm{~s}$ with a BA Optima 10 curing light (BA International Ltd., Northampton, Northamptonshire, UK).

Group II and III teeth were acid etched, rinsed and airdried (as outlined above). The occlusal surfaces were then contaminated with $0.1 \mathrm{~cm}^{3}$ of either distilled water (Group II) or fresh saliva (Group (III) for $20 \mathrm{~s}$ using a dropping pipette and then lightly dried using a cotton pellet which was applied for $5 \mathrm{~s}$, prior to the application of the sealant [3].

Laser conditioning of the occlusal surfaces of Group IV teeth was carried out using an Er:YAG laser system (LightWalker ${ }^{\circledR}$, Fotona, Slovenia) operating at a wavelength of $2940 \mathrm{~nm}$, a power output of $1.2 \mathrm{~W}$, pulse energy of $120 \mathrm{~mJ}$ and a frequency of $10 \mathrm{~Hz}$. Laser ablation was carried out using a $600 \mu \mathrm{m}$ diameter sapphire tip with a beam spot size of $0.63 \mathrm{~mm}^{2}$, energy density of $19 \mathrm{~mJ} \mathrm{~cm}{ }^{2}$ at a working distance of $8 \mathrm{~mm}$ at an angle of $90^{\circ}$ under water cooling at $50 \mathrm{~cm}^{3} \mathrm{~min}^{-1}$. The teeth were then rinsed with water, air-dried and acid etched, as described above, prior to the application and curing of the UltraSeal $\mathrm{XT}^{\circledR}$ hydro $^{\mathrm{TM}}$ sealant. Groups V and VI teeth were sequentially lased and acid etched (as outlined above). The occlusal surfaces of Group V were contaminated with distilled water and Group VI teeth were contaminated with fresh saliva prior to the application of the sealant.

\section{Microleakage analysis}

Immediately after sealing, the teeth were placed in distilled water at $37^{\circ} \mathrm{C}$ for $24 \mathrm{~h}$ and then thermocycled 3000 times between 5 and $55^{\circ} \mathrm{C}$ with a transfer time of $10 \mathrm{~s}$ and a dwell time of $30 \mathrm{~s}[4,5]$. Subsequent microleakage was assessed via dye penetration. The teeth were coated with nail varnish, leaving a $2 \mathrm{~mm}$ window around the sealant, and the roots were embedded in an acrylic resin cylinder (Meliodent, Bayer Dental, UK). The teeth were then placed in 0.5\% basic fuchsin dye solution for $24 \mathrm{~h}$. Following immersion, the teeth were rinsed under running tap water for $5 \mathrm{~min}$ to remove excess dye and sectioned in the buccolingual direction using a water-cooled diamond saw to obtain three slices. Each of the tooth sample slices was then examined by two blind investigators under a stereomicroscope (SMZ 800, Nikon, Japan) at 20× magnification. Microleakage scoring criteria are listed in Table 2 [11].

Inter-examiner reproducibility was analysed with the kappa statistic. Median differences among the microleakage data for each of the groups were compared using the Kruskal-Wallis test $(p=0.05)$. Significant differences were evaluated using the Mann-Whitney $U$ test with Bonferroni adjustment $(p=0.05)$. 
Table 2 Microleakage scoring criteria

\begin{tabular}{ll}
\hline Score & Definition \\
\hline 0 & No dye penetration \\
1 & Dye penetration up to half of the fissure \\
2 & Dye penetration beyond half of the fis- \\
& sure without total involvement \\
3 & Dye penetration to the sealant base \\
\hline
\end{tabular}

\section{Scanning electron microscopy}

Scanning electron microscopy was carried out on the central slices of the sectioned teeth using uncoated samples attached to carbon tabs on a JEOL JSM-5410 LV electron microscope with an Oxford Instruments X-MaxN EDX detector in low vacuum mode. All back-scattered electron images and EDX maps were obtained with an accelerating voltage of $20 \mathrm{kV}$ at a working distance of $20 \mathrm{~mm}$.

\section{Results}

\section{Microleakage analysis}

The distributions of microleakage scores for each experimental group are listed in Table 3. An inter-examiner kappa statistic of 0.90 was obtained for the microleakage evaluation which indicates high reproducibility.

No significant difference in marginal leakage was found between the separately acid etched groups that were either air-dried (Group I) or saliva-contaminated (Group III) $(p=0.09)$, although the number of samples that exhibited no visible microleakage was greater in the former case. Conversely, Group II teeth that were acid etched and water-contaminated exhibited significantly higher microleakage than those of both Group I $(p<0.001)$ and Group III $(p<0.001)$. Hence, the null hypothesis that there is no difference in microleakage between acid etched samples that were airdried or moist is rejected in the case of water contamination, but retained in the case of saliva contamination. None of the samples in Group II was entirely resistant to dye penetration, with over half of the specimens in this group exhibiting maximum penetration to the sealant base. Furthermore, the sealant partially detached (i.e. 'debonded') from the central section of one of the samples in the water-contaminated group prior to inspection for microleakage.

In all cases, irrespective of whether the teeth were airdried or contaminated with either water or saliva, laser ablation as an adjunct to acid etching was found to significantly improve resistance to microleakage $(p<0.05)$. The median and modal microleakage scores for Groups IV, V, and VI were zero, indicating that the majority of the lased samples completely resisted dye penetration. Among these groups, there were no significant differences in microleakage irrespective of the presence or absence of either water or saliva. Therefore, the null hypothesis that enamel pre-conditioning by laser ablation prior to acid etching has no impact on microleakage is rejected across all groups. Conversely, the null hypothesis that water or saliva contamination does not influence microleakage of sealed teeth that have been consecutively lased and acid etched is retained.

\section{Scanning electron microscopy}

The back-scattered electron image of the enamel-sealant interface of a random Group I acid etched air-dried tooth is shown in Fig. 1 along with the corresponding EDX elemental maps of carbon, barium, silicon and aluminium. In this group, the sealant was well adapted to the acid etched air-dried enamel and the barium-, aluminium- and siliconbearing inorganic filler phases remained homogeneously distributed throughout the organic resin matrix.

SEM analysis indicated that Group II acid etched watercontaminated samples were characterised by relatively wide gaps of several tens of microns between the sealant and the enamel (Fig. 2). It is likely that the low vacuum pressure of approximately $15 \mathrm{~Pa}$ encountered in the electron microscope caused the poorly adapted sealant of the water-contaminated samples to detach from the enamel. On the contrary, the
Table 3 Microleakage scores as functions of moisture and enamel conditioning

\begin{tabular}{lrrrrlll}
\hline Score & 0 & 1 & 2 & 3 & Debonded & Median & $\begin{array}{l}\text { Sig- } \\
\text { nifi- } \\
\text { cance* }\end{array}$ \\
\hline Group I & 10 & 12 & 4 & 4 & 0 & 1 & $\mathrm{a}$ \\
Group II & 0 & 6 & 6 & 17 & 1 & 3 & $\mathrm{~b}$ \\
Group III & 2 & 16 & 8 & 4 & 0 & 1 & $\mathrm{a}$ \\
Group IV & 20 & 7 & 0 & 2 & 0 & 0 & $\mathrm{c}$ \\
Group V & 17 & 9 & 1 & 3 & 0 & 0 & $\mathrm{c}$ \\
Group VI & 16 & 6 & 6 & 2 & 0 & 0 & $\mathrm{c}$ \\
\hline
\end{tabular}

* Different letters indicate significant differences among the groups $(p<0.05)$, whereas the same letters indicate no significant differences $(p>0.05)$ 

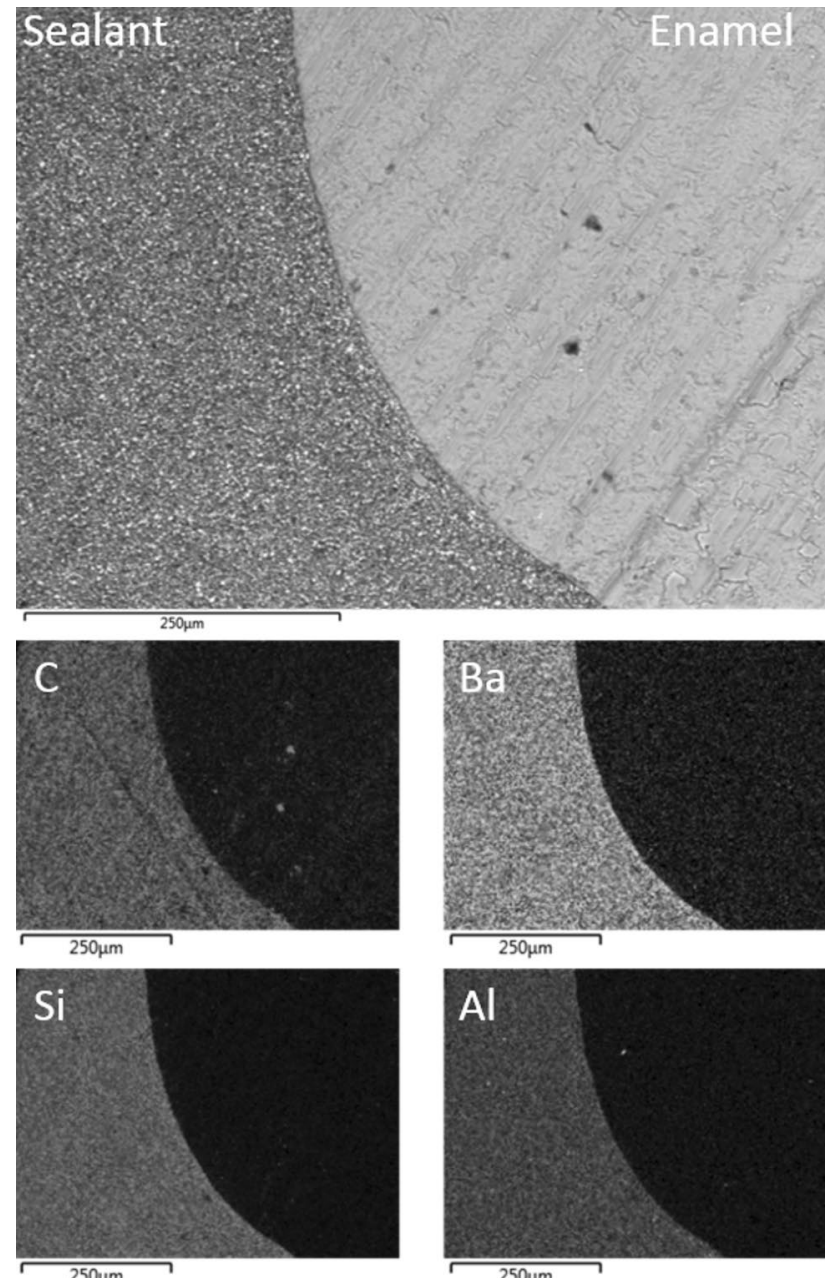

Fig. 1 Back-scattered SEM image of UltraSeal $\mathrm{XT}^{\circledR}$ hydro $^{\mathrm{TM}}$ in contact with Group I air-dried acid etched enamel; and corresponding EDX maps of carbon, barium, silicon and aluminium

sealant was generally observed to be in intimate contact with the saliva-contaminated enamel of the Group III teeth, with occasional margins of a few microns (Fig. 3). The inorganic filler phases were seen to be uniformly distributed throughout the organic resin matrix of the sealant in Groups II and III.

Representative back-scattered electron micrographs of the interfaces of the sealant and the laser pre-conditioned enamel of Groups IV, V, and VI are shown in Figs. 4, 5, and 6 , respectively. In all cases, the sealant was observed to be in direct contact with the enamel. These samples also exhibited regions of sub-surface enamel cracking at depths of up to $150 \mu \mathrm{m}$ from the interface. Some zoning of the inorganic filler particles at the enamel-sealant interface was noted for samples in Groups IV and V (Figs. 4, 5, respectively), although the filler remained homogeneously distributed in the Group VI specimens. The increased concentration of the filler at the enamel surface is attributed to the enhanced
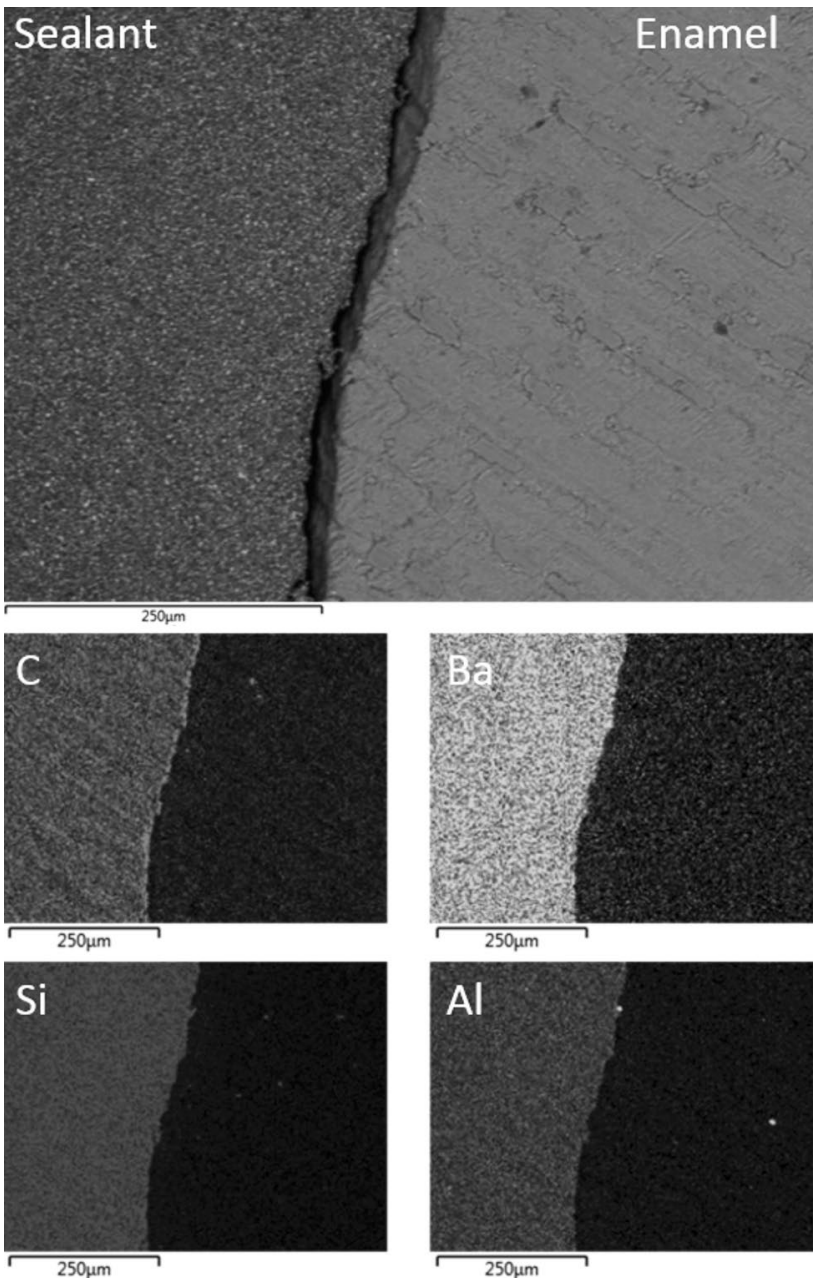

Fig. 2 Back-scattered SEM image of UltraSeal $\mathrm{XT}^{\circledR}{ }^{\circledR}$ hydro ${ }^{\mathrm{TM}}$ in contact with Group II water-contaminated acid etched enamel; and corresponding EDX maps of carbon, barium, silicon and aluminium

surface roughness of the lased enamel [4,5], which appears to be mitigated by the lubricating effect of saliva.

\section{Discussion}

UltraSeal $\mathrm{XT}^{\circledR}$ hydro $^{\mathrm{TM}}$ is a recently marketed moisture-tolerant, self-adhesive, acrylate-based pit and fissure sealant which has been developed by Ultradent Products, USA [4]. It is highly filled with 53\% inorganic phases which are incorporated to confer radiopacity and to improve wear-resistance. UltraSeal $\mathrm{XT}^{\circledR}$ hydro ${ }^{\mathrm{TM}}$ is reported to 'chase' moisture into the pits and fissures, thus eliminating moisture-related failures in adaptation and retention which are common to hydrophobic sealant materials [10].

Since this is a new material, at the present time, only one report could be located in the scientific literature concerning the relative sealing performance of UltraSeal $\mathrm{XT}^{\circledR}$ hydro $^{\mathrm{TM}}$ 

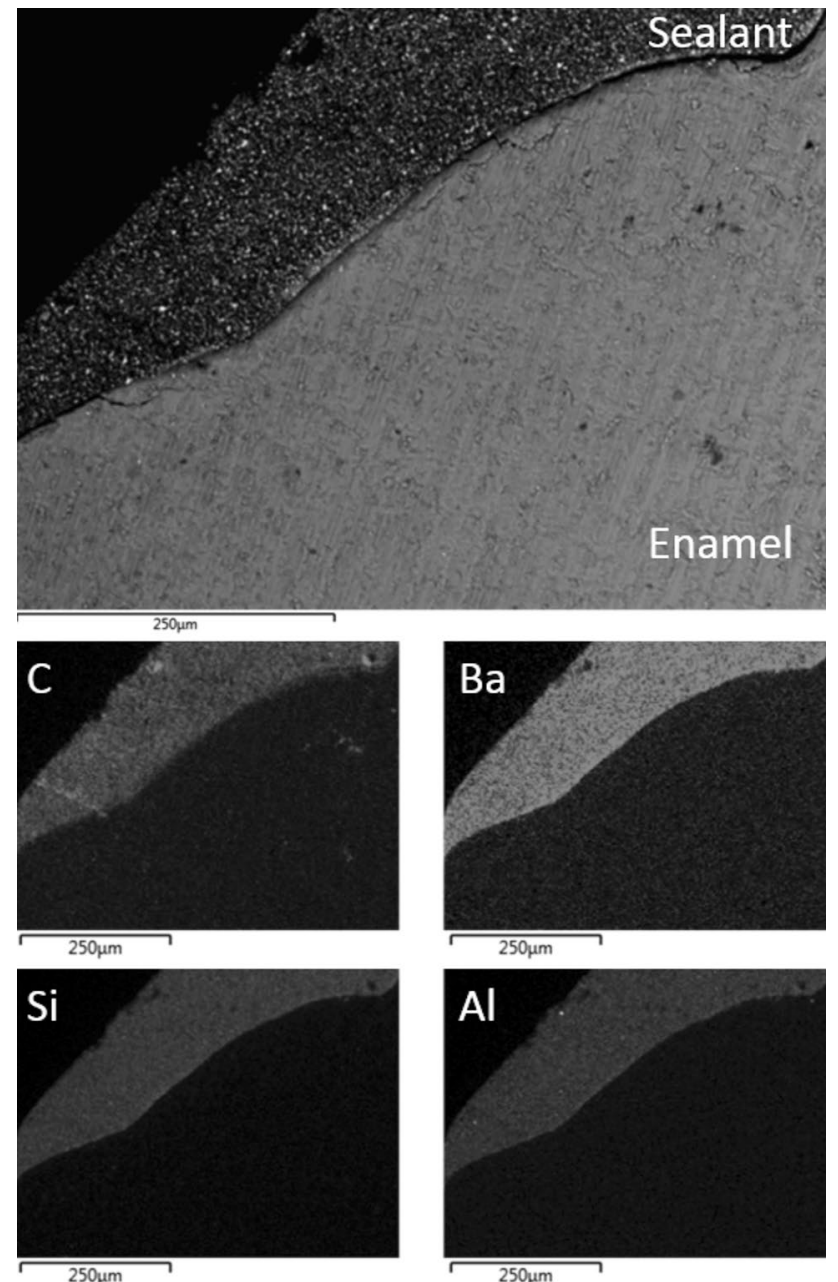

Fig. 3 Back-scattered SEM image of UltraSeal $\mathrm{XT}^{\circledR}{ }^{\circledR}$ hydro $^{\mathrm{TM}}$ in contact with Group III saliva-contaminated acid etched enamel; and corresponding EDX maps of carbon, barium, silicon and aluminium

on air-dried or saliva-contaminated primary second molars [12]. This research confirms the manufacturer's claim that surface contamination by saliva does not affect the sealing ability of this material; although, the impact of water contamination is not addressed in the study. Our present results also confirm that, after 3000 thermocycles between 5 and $55^{\circ} \mathrm{C}$, there is no difference in the extent of dye penetration when UltraSeal $\mathrm{XT}^{\circledR}$ hydro ${ }^{\mathrm{TM}}$ is placed on conventionally etched enamel that is either air-dried or saliva-contaminated. To best identify any differences in sealing ability among the various experimental groups, our microleakage study employed relatively aggressive thermocycling parameters and $0.5 \%$ basic fuchsin solution which is considered the most effective dye for revealing microleakage [5].

Conversely, our results indicate that UltraSeal $\mathrm{XT}^{\circledR}$ hydro $^{\mathrm{TM}}$ does not effectively tolerate contamination by water to the same extent that it tolerates saliva. In the case of water contamination, wide gaps between the sealant and enamel
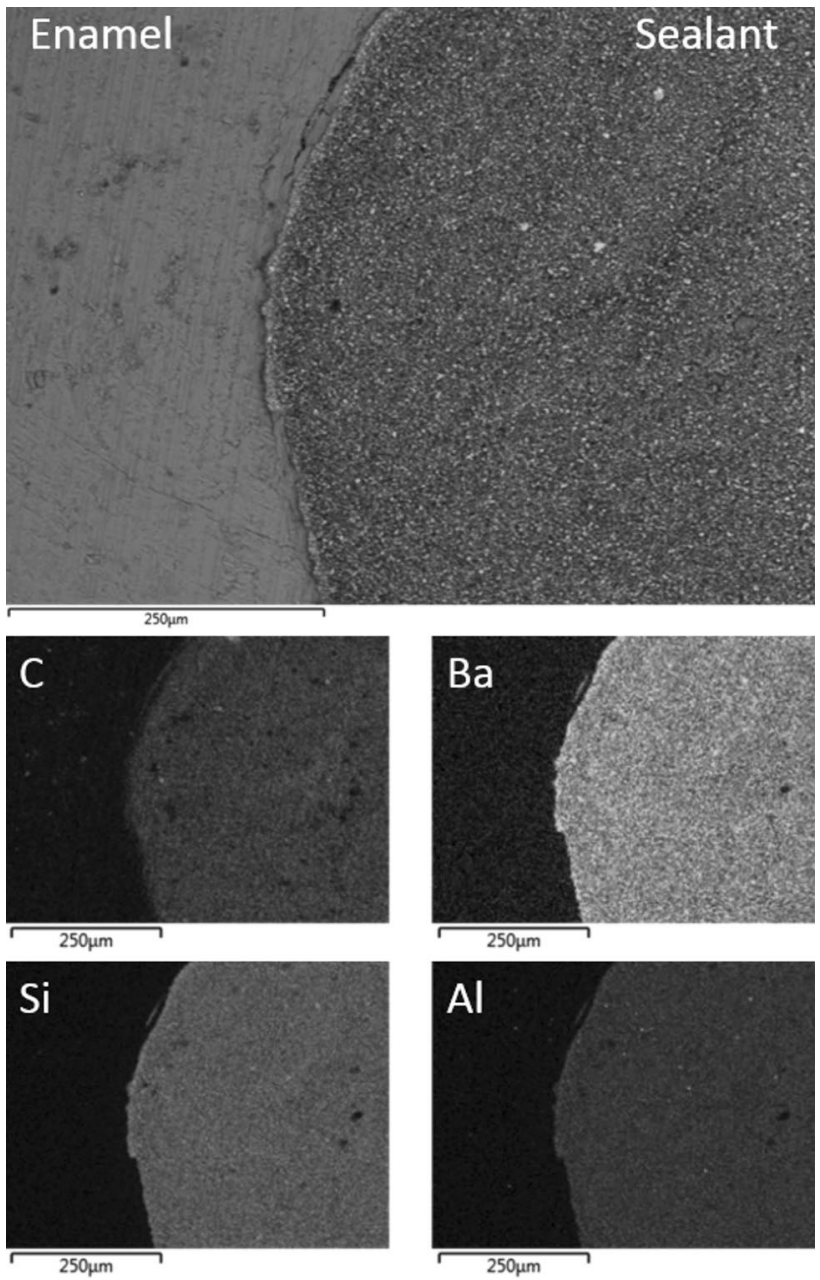

Fig. 4 Back-scattered SEM image of UltraSeal $\mathrm{XT}^{\circledR}$ hydro $^{\mathrm{TM}}$ in contact with Group IV air-dried etched and lased enamel; and corresponding EDX maps of carbon, barium, silicon and aluminium

were noted in all corresponding SEM images, and the relative resistance to dye penetration was diminished.

The direct clinical relevance of in vitro microleakage tests is questionable, although it is generally agreed that they can provide useful information on a dental sealant's capacity to maintain good marginal adaptation to prevent bacterial ingress. The potential clinical significance of this study is that caution should be applied when considering the nature of the moisture contamination present at the time of placement and sealing with UltraSeal $\mathrm{XT}^{\circledR}$ hydro ${ }^{\mathrm{TM}}$, as, in this respect, a discrepancy in performance has been identified between water and saliva.

Recent reports by the authors $[4,5]$ have demonstrated that teeth treated with a successive combination of Er:YAG laser irradiation and acid etching prior to sealing with UltraSeal $\mathrm{XT}^{\circledR}$ hydro $^{\mathrm{TM}}$ showed significantly lower microleakage scores than those that were exclusively acid etched. These studies included only air-dried enamel and did not consider 

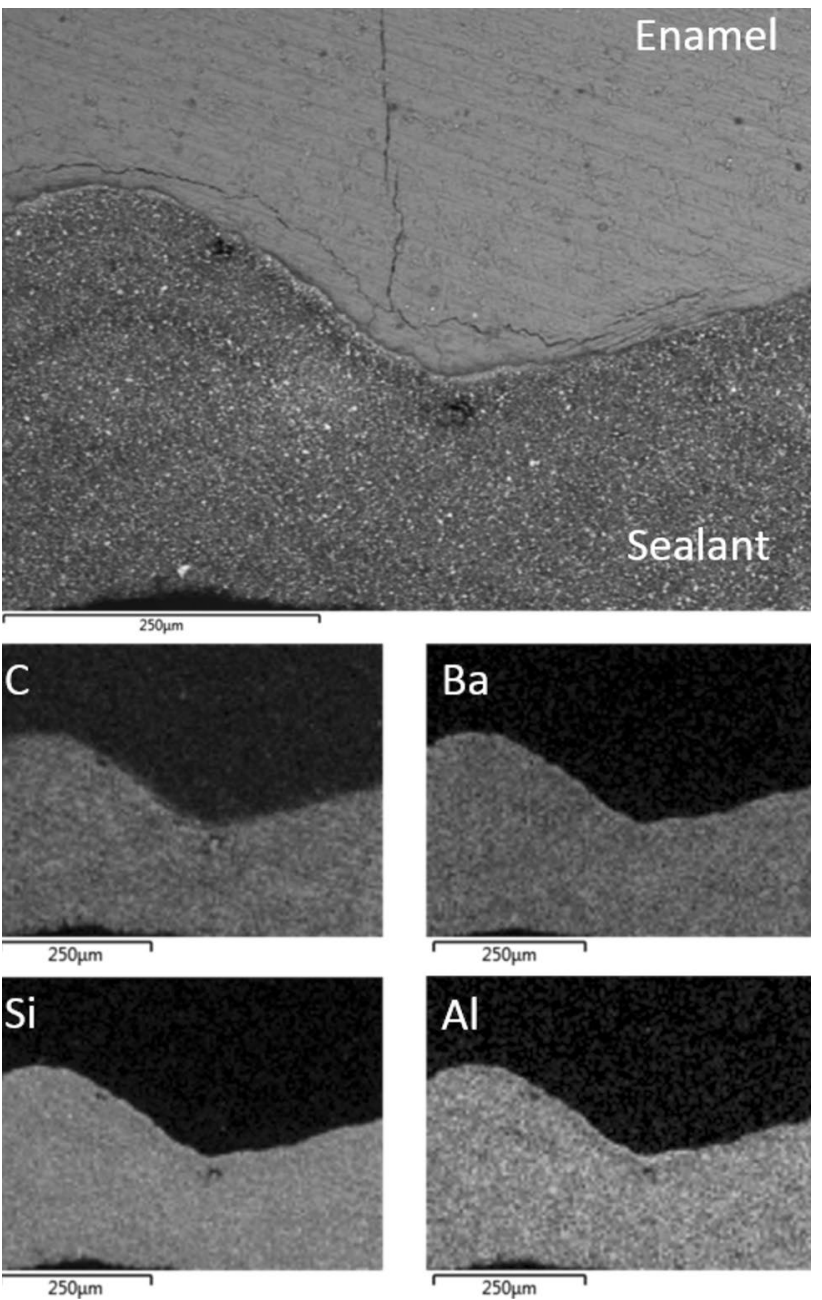

Fig. 5 Back-scattered SEM image of UltraSeal $\mathrm{XT}^{\circledR}$ hydro $^{\mathrm{TM}}$ in contact with Group V water-contaminated etched and lased enamel; and corresponding EDX maps of carbon, barium, silicon and aluminium

the impact of moisture contamination on sealing ability. From the results obtained in our present study, it appears that laser pre-conditioning prior to acid etching improves resistance to microleakage irrespective of whether the enamel is air-dried or contaminated with either water or saliva. These findings concur with those of a similar study on another commercial hydrophilic sealant (Embrace WetBond ${ }^{\mathrm{TM}}$, Pulpdent/Gaba, USA) which demonstrated significant improvements in resistance to microleakage for laser pre-conditioned enamel which was contaminated with either water or saliva [3].

There is, currently, no universal agreement regarding the potential benefits of laser pre-conditioning on the retention and microleakage of self-adhesive resin-based fissure sealants. For example, studies by Ciucchi et al. [7], Borsatto et al. [8] and Youssef et al. [13] report no significant differences in hydrophobic sealant microleakage
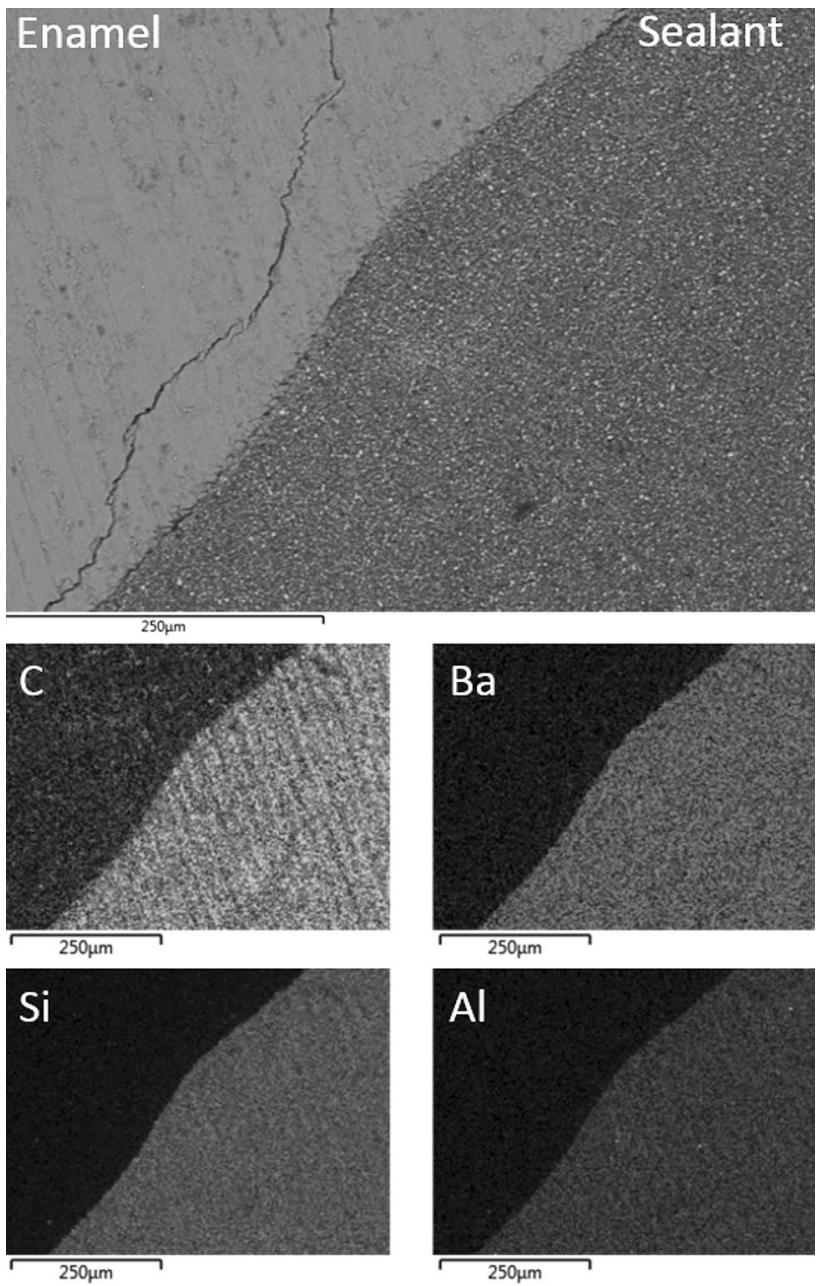

Fig. 6 Back-scattered SEM image of UltraSeal $\mathrm{XT}^{\circledR}{ }^{\circledR}$ hydro $^{\mathrm{TM}}$ in contact with Group VI saliva-contaminated etched and lased enamel; and corresponding EDX maps of carbon, barium, silicon and aluminium

between teeth that were exclusively acid etched and those that were consecutively Er:YAG laser ablated and acid etched. It is speculated that highly viscous sealants adapt poorly to the enhanced roughness of lased enamel, which may account for the observed discrepancies in the literature.

A further consideration associated with the application of laser-pre-conditioning is the occurrence of sub-surface enamel cracking that has been noted in this and previous studies $[4,5,14]$. The presence of sub-surface microcracking is not visible to the clinician, and is also not readily observed in vitro using light microscopy, so the reported incidences are limited to the few studies in which scanning electron microscopy has been employed. At this point in time, the significance of laser-induced microcracking with respect to the longevity of the sealant and the ongoing welfare of the tooth has not yet been determined. 


\section{Conclusions}

This study concerns the impact of Er:YAG laser pre-conditioning and moisture contamination on the microleakage of a recent hydrophilic sealant (UltraSeal $\mathrm{XT}^{\circledR}{ }^{\circledR}$ hdro $^{\mathrm{TM}}$ ). No significant difference was observed in microleakage of acid etched teeth that were either air-dried or saliva-contaminated; unlike their water-contaminated counterpart which exhibited more extensive dye penetration. Laser pre-conditioning prior to conventional acid etching significantly increased resistance to microleakage irrespective of whether the enamel surface was moist or dry. Scanning electron microscopy (SEM) demonstrated good adaptation in all cases with the exception of water-contaminated acid etched teeth which exhibited relatively wide gaps between the sealant and enamel. SEM analysis also revealed subsurface cracking of the enamel of teeth subjected to laser ablation.

\section{Compliance with ethical standards}

Conflict of interest The authors declare that they have no conflict of interest.

Open Access This article is distributed under the terms of the Creative Commons Attribution 4.0 International License (http://creativecommons.org/licenses/by/4.0/), which permits unrestricted use, distribution, and reproduction in any medium, provided you give appropriate credit to the original author(s) and the source, provide a link to the Creative Commons license, and indicate if changes were made.

\section{References}

1. Simonsen RJ, Neal RC. A review of the clinical application and performance of pit and fissure sealants. Aust Dent J. 2011;56(1 Suppl):45-58.

2. Sezinando A. Looking for the ideal adhesive-a review. Rev Port Estomatol Med Med Dent Cir Maxilofac. 2014;55:194-206.
3. Khogli AE, Cauwels R, Vercruysse C, Verbeeck R, Martens L. Microleakage and penetration of a hydrophilic sealant and a conventional resin-based sealant as a function of preparation techniques: a laboratory study. Int J Paediatr Dent. 2013;23:13-22.

4. Güçlü ZA, Dönmez N, Hurt AP, Coleman NJ. Characterisation and microleakage of a new hydrophilic fissure sealant-UltraSeal $\mathrm{XT}^{\circledR}$ hydro $^{\mathrm{TM}}$. J Appl Oral Sci. 2016;24:344-51.

5. Güçlü ZA, Dönmez N, Tüzüner T, Odabaş ME, Hurt AP, Coleman NJ. The impact of Er:YAG laser enamel conditioning on the microleakage of a new hydrophilic sealant-UltraSeal $\mathrm{XT}^{\circledR}$ hydro $^{\text {TM }}$. Lasers Med Sci. 2016;31:705-11.

6. Durmus B, Giray F, Peker S, Kargul B. Clinical evaluation of a fissure sealant placed by acid etching or Er:YAG laser combined with acid etching. Oral Health Prev Dent. 2017;15:157-62.

7. Ciucchi P, Neuhaus KW, Emerich M, Peutzfeldt A, Lussi A. Evaluation of different types of enamel conditioning before application of fissure sealant. Lasers Med Sci. 2015;30:1-9.

8. Borsatto MC, Corona SAM, Palma-Dibb RG, Ramos RP, Pecora JD. Microleakage of a resin sealant after acid-etching, Er:YAG laser irradiation and air-abrasion of pits and fissures. J Clin Laser Med Surg. 2001;19:83-7.

9. Sungurtekin-Ekci E, Oztas N. Microtensile bond strength of a resin-based fissure sealant to Er, Cr:YSGG laser-etched primary enamel. Odontology. 2016;104:163-9.

10. Brinker SP. Preventing carious lesions. Clinical steps for applying a newly introduced hydrophilic sealant. Dent Today. 2013;32:82-3.

11. Hossain M, Yamada Y, Masuda-Murakami Y, Nakamura Y. Removal of organic debris with Er:YAG laser irradiation and microleakage of fissures sealants in vitro. Lasers Med Sci. 2012;27:895-902.

12. Gawali PN, Chaugule VB, Panse AM. Comparison of microleakage and penetration depth between hydrophilic and hydrophobic sealants in primary second molar. Int J Clin Pediatr Dent. 2016;9:291-5.

13. Youssef MN, Youssef FA, Souza-Zaroni WC, Trbino ML, Vieira MM. Effect of enamel preparation method on in vitro marginal microleakage of a flowable composite used as a pit and fissure sealant. Int J Paediatr Dent. 2006;16:342-7.

14. Rodriguez-Vilchis LE, Contreras-Bulnes R, Sanchez-Flores I, Samano EC. Acid resistance and structural changes of human dental enamel treated with Er:YAG laser. Photomed Laser Surg. 2010;28:207-11. 